\title{
AGRICULTURA E FUTEBOL: RESISTÊNCIAS E AJUSTAMENTOS NO USO DO TERRITÓRIO NA ALDEIA DE RENQUE PURGA, ILHA DE SANTIAGO, CABO VERDE
}

\author{
Vladmir Antero Delgado Silves Ferreira ${ }^{1}$
}

Em Dezembro de 2004 por razões profissionais passei a fazer diariamente o trajeto Praia/São Miguel/Praia. Este percurso de pouco mais de uma hora e meia (cerca de $70 \mathrm{~km}$ ) e que atravessa os Municípios da Praia, São Domingos, Santa Cruz e São Miguel, permitia-me contemplar a diversidade paisagística da Ilha de Santiago ao longo deste trajeto. Santiago é a maior de um conjunto de dez ilhas que compõem o Arquipêlago de Cabo Verde e fica situado na costa ocidental de África, a cerca de 500 km do Senegal e da Guiné-Bissau, e quase no meio do Atlântico onde a África fica mais perto da América do Sul.

Uma criança inocente trajando a sua bata azul caminhando e brincando nas bermas da estrada a caminho da escola sem consciência dos perigos que representa o fluxo e a intensidade de trafego dos Hiaces $^{2}$ rodando sempre de forma apressada e ao som dos ritmos sonoros do último grito da moda musical; uma vistosa figueira que se ergueu no sopé de uma montanha indiferente à secura e aridez da paisagem circundante; o sistema de sinais desenvolvido pelos motoristas de Hiaces que trocam uma gama de informações gestuais, sonoras e luminosas quando se cruzam na estrada sem abrandar a marcha fazendo relembrar o frenético ir e vir das formigas; os diálogos e as amizades que fui fortalecendo com os colegas de jornada; a arquitetura das pequenas vivendas familiares; a imponência das igrejas... Enfim, um leque de imagens, momentos e situações que foram enchendo o meu imaginário e que acrescentaram na minha consciência outros elementos, dinâmicas e vivências da Ilha de Santiago.

Contudo uma situação sui generis conquistou de forma particular a minha atenção, minha curiosidade e de certa forma também o meu encanto. Observando o milheiral à entrada do Município de Santa Cruz, mais concretamente no Vilarejo de Renque Purga deparei-me com duas balizas ${ }^{3}$ aparentemente distanciadas entre si dentro

\footnotetext{
${ }^{1}$ Universidade de Cabo Verde e Escola Superior de Ciências Agrárias e Ambientais, Cabo Verde.

${ }^{2}$ Veículo minibus de fabricação japonesa que faz o transporte interurbano de passageiros. Para mais informações consultar: HORTA, G \& D. Calvo. 2014. Hiace. Antropología de las carreteras en la isla de Santiago (Cabo Verde). Pol.len Edicions

3 "Balizas" é a terminologia utilizada pelos falantes da língua Portuguesa de Portugal e da generalidade dos restantes países lusófonos africanos e é equivalente à expressão "gol” na variante brasileira.
} 
dos parâmetros regulamentares de um campo de futebol de onze ${ }^{4}$. Numa primeira abordagem a minha interpretação foi no sentido de que ali existia um antigo campo de futebol desativado e que foi posteriormente transformado em campo de cultivo de sequeiro.

Porém, continuei a fazer este trajeto nos nove meses seguintes o que permitiu-me acompanhar todo o processo de transformação no uso do território em que a agricultura, enquanto atividade geradora de rendimentos, e o futebol, enquanto atividade desportiva e de lazer, encontraram um espaço de ajustamentos e de coexistência. O objetivo do presente trabalho é fazer uma reflexão em torno de algumas questões históricas e sociológicas, que possam ajudar à compreensão destes dois fenómenos (futebol e agricultura) marcantes da cultura cabo-verdiana.

Em Renque Purga na época das chuvas se pratica agricultura e na época seca se retoma à prática de atividades desportivas. Este quadro paisagístico suscitou a minha atenção pela sua singularidade e sobretudo por evidenciar num micro-espaço uma diversidade de questões. Como diria Jean-Yves Durand (2003, p. 20), “... não é por um jogo de futebol e a cultura das couves precisarem ambos de um campo e se desenvolverem ao ar livre que têm de ser abordados nos mesmos termos". Porém esta questão ganha outras dimensões quando as duas atividades humanas se praticam num mesmo espaço, quando campus de interação entre lógicas de ocupação do território, consideradas antagónicas, se harmonizam e se coabitam permitindo assim que sejam abordados pelos mesmos parâmetros.

Dez anos depois regresso a Renque Purga para através de uma "etnografia fotografada" lançar um olhar sobre este locus de relação natureza e sociedade tendo como categoria de análise a paisagem e as estratégias de ocupação do território. Ao longo de dez meses, num total de seis deslocações ao local, recolhi uma sequência fotográfica dos vários momentos de ocupação deste micro-espaço, um pequeno vilarejo, nos arredores do Município de Santa Cruz, Ilha de Santiago. As seis deslocações ocorreram entre os meses de Março, Maio, Agosto, Outubro e Dezembro de 2014. Destas deslocações resultaram numa sequência de 50 registos fotográficos, dos quais

\footnotetext{
${ }^{4}$ Desporto de equipe jogado entre dois times de 11 jogadores cada um e um trio de árbitros que se ocupa da correta aplicação das normas. É jogado num campo retangular gramado, com uma baliza em cada lado do campo. O objetivo do jogo é deslocar uma bola através do campo para colocá-la dentro da baliza adversária, ação que se denomina golo (português europeu) ou gol (português brasileiro). A equipe que marca mais gols ao término da partida é a vencedora,
} 
selecionei quatro, que me serviram de base de análise com vista à produção desta reflexão.

De modo geral os trabalhos de pesquisa são normalmente apresentados na forma verbal e escrita. Tal supremacia conferida ao texto e à palavra se deve, por certo, às práticas acadêmicas de sempre, cuja pertinência científica não costuma ser colocada em questão. Contudo, conforme defende Achutti (2003), mesmo sendo o texto fundamental, a sua associação a outras formas narrativas só pode enriquecer os enunciados antropológicos.

\begin{abstract}
Poucos trabalhos de antropologia utilizaram a fotografia de maneira significativa, o que sem dúvida deve-se atribuir à forte tradição escrita que reina nas ciências humanas em geral e na antropologia em particular. Na maioria dos trabalhos a fotografia aparece como elemento secundário e, como se pode constatar percorrendo estes trabalhos, deve-se imputar a responsabilidade deste fato aos próprios pesquisadores que atribuíram um papel secundário à linguagem fotográfica... (Achutti, 2003, s/p).
\end{abstract}

É verdade que encontramos poucas imagens em trabalhos de pesquisa, tais como dissertações de mestrado, teses de doutoramento, artigos publicados em revistas especializadas, livros, etc., e quando existem realmente não assumem um papel de centralidade na difusão da mensagem que se pretende transmitir. Tal situação se deve ao fato de que, apesar da fotografia se ter tornado tecnicamente mais acessível nos tempos mais recentes, ela requer, além de um certo tempo de prática, uma boa compreensão de sua linguagem. É pelas mesmas razões também - pouca prática e pouco conhecimento que muitos pesquisadores frustram-se quando empregam a fotografia nos seus trabalhos.

Também me incluo no grupo (da grande maioria) dos pesquisadores que pouco ou quase nada entendem em termos de técnica e/ou arte de fotografar. Assim proponho construir uma narrativa tendo como elemento central uma sequência de imagens captadas a partir do meu olhar leigo e que corresponde a um quadro cronológico construído com base nas minhas próprias referências para a construção de um texto que representa o meu observar sobre a paisagem em estudo.

Obviamente que a complementaridade entre texto e fotografia em um mesmo trabalho pode ser interessante, mas para isso é fundamental que esses dois meios componham dois momentos independentes e solidários a serviço daquilo que o pesquisador quer transmitir. Desta forma uma narrativa informa a outra, e as duas juntas informam o leitor (Achutti, 2003, s/p). 
De acordo com Bertrand (1995 apud Verdum, 2008) a análise de paisagens é de extrema importância, pois através dela é possível compreender, em parte, a complexidade do espaço geográfico em um determinado momento do seu processo evolutivo. A paisagem é resultado da vida das pessoas, dos processos produtivos e da transformação da natureza. Neste sentido, ela mostra a história da população de um determinado lugar e que necessita sempre estar sendo discutida e registada.

Para as pessoas em geral, o termo paisagem sugere duas maneiras distintas de ser entendido: a de visão objetiva e a de representação. A ideia da paisagem como visão objetiva é baseada naquilo que a visão alcança; ou seja, a visão possibilita que se construa a noção de paisagem como um mosaico mais ou menos ordenado de formas e cores. O alcance e os limites da visão nos permitem estabelecer a noção de escala espacial da paisagem (Verdum, 2009). Ao nos transferirmos no tempo, notamos que o mesmo recorte espacial dado pela visão se altera, isto é, a paisagem é dotada de uma dinâmica que nos permite estabelecer para a paisagem também a noção de escala temporal. Todos os elementos que compõem essa dinâmica podem ser objetos de estudo, tanto em conjunto como isoladamente. No entanto, essa dinâmica sugere uma estrutura e um funcionamento essencialmente únicos, características que dariam a cada paisagem seu caráter específico.

Na ciência, a conceção de paisagem tem-se diferenciado, como as associações que são feitas com as noções de país, lugar, unidade territorial e porção da superfície de terra firme. No limiar de sua elaboração como referencial de expressão artística e de análise das relações entre sociedade e natureza. Segundo Verdum (2009), duas construções lógicas são apresentadas na conceituação de paisagem:

1) Como a imagem que representa a vista de um recorte espacial, expressa na arte produzida sobretudo a partir do século XVII, com significado pictórico/subjetivo, com a finalidade de expressar elementos associados à natureza e à vida do cotidiano das sociedades humanas;

2) Como a porção da superfície terrestre vista em seu conjunto e como o produto de uma área modificada pelas forças geológicas e geomorfológicas, com significado objetivo, onde buscamos compreender a origem da forma, da estrutura e da funcionalidade associadas a um número específico de elementos da natureza. 
Diria que os dois pressupostos são complementares mas a minha perspetiva de análise se centrará sobretudo a partir de imagens recolhidas e procurarei expressar as componentes associadas à natureza e à vida das pessoas neste campus delimitado que é simultaneamente espaço de recriação desportiva e de produção agrícola.

\section{Tarde de Seca Peli}

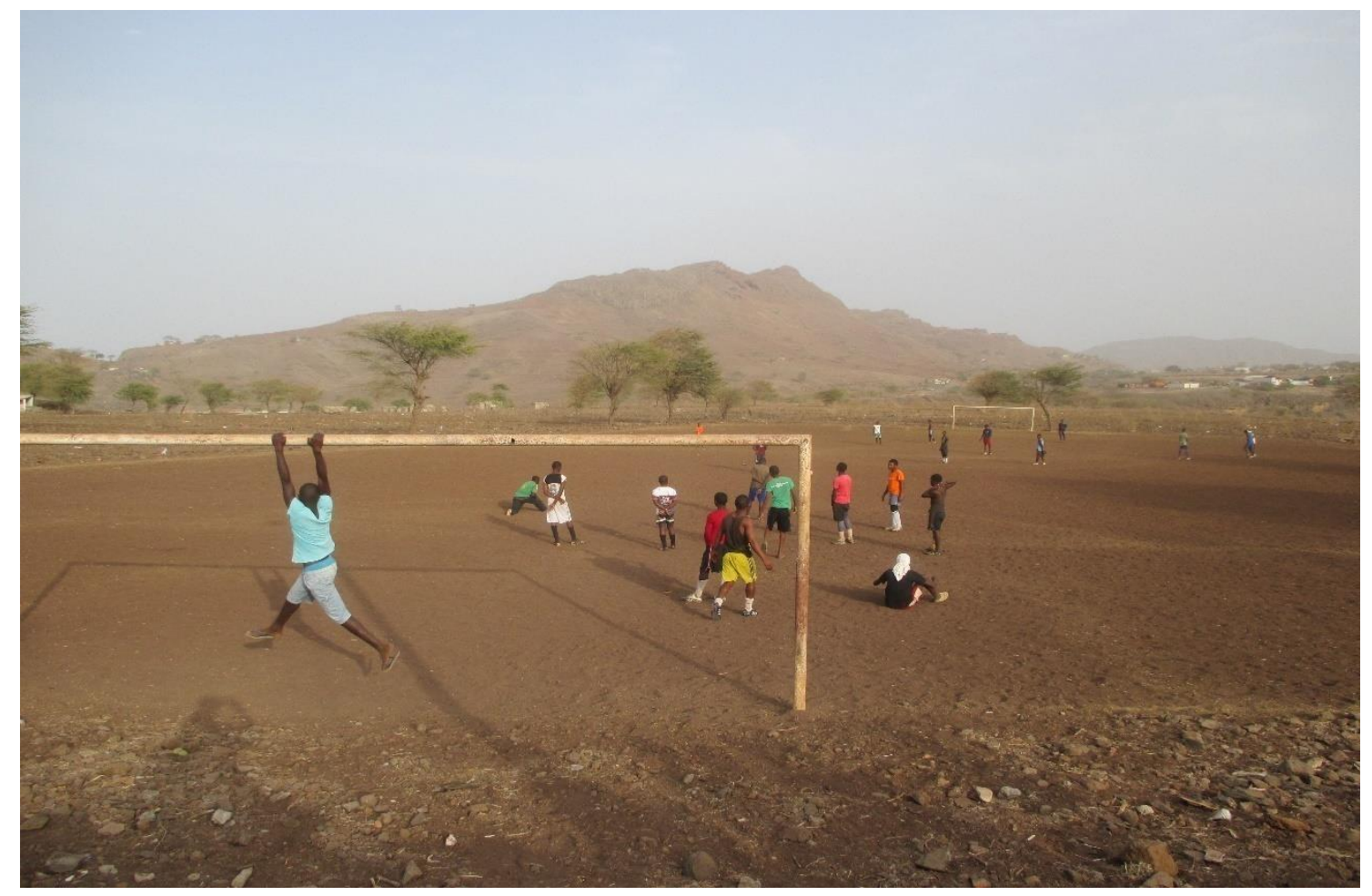

15 de Março de 2014.

Uma vintena de jovens/adolescentes se preparam para iniciar uma tarde de Seca Peli no campo de Renque Purga. Esta expressão é utilizada para se referir à uma partida de futebol improvisada entre amigos num campo de terra batida. As regras são bastante flexíveis e variam em função da dinâmica do jogo. Não existe a figura do árbitro (juiz da partida) nem tempo determinado para o seu término. Não há uniformização na indumentária dos jogadores e se joga com os pés descalços ou com sapatos inapropriados.

Em tempos era praticado com bolas improvisadas de "trapos e farrapos". Todavia hoje o acesso a este objeto lúdico se tem tornado mais acessível às camadas sociais menos favorecidas, sobretudo com a proliferação das lojas e casas de comércio de

\footnotetext{
${ }^{5}$ Pedaços de panos velhos.
} 
produtos Made in China. Acredito que Seca Peli possa ser uma derivação da expressão pelada $^{6}$ de futebol comumente utilizada no Brasil.

Seca Peli se afigura como uma alternativa às chamadas Escolinhas de Futebol cada vez mais comuns nos centros urbanos e menos acessíveis aos meninos provenientes de famílias de baixa renda das periferias mais pobres ou dos espaços rurais. Práticas que se aproximam às origens do futebol que na sua fase inicial se desenvolveu como atividade de rua, de sociabilidades (sobretudo masculina) e de ocupação de tempo-livre e recriação artística.

O campo de futebol de Renque Purga se posiciona assim na contracorrente do futebol moderno que se assume cada vez mais como instituição disciplinadora e civilizadora, dotada de regras, normas e princípios científicos, tendo como objetivo produzir, manipular, individualizar, adestrar e aperfeiçoar o corpo do indivíduo, tornar o jogador dócil e utilitário (Rodrigues, 2004), conforme nos elucida Gilson Gil (1994) num artigo em que analisa as mudanças ocorridas no futebol brasileiro na década de 70 .

O "futebol-arte" praticado por "malandros", "mulatos" e "dançarinos" começou a ser questionado em seu primado sobre o imaginário futebolístico do Brasil. Instalou-se uma crítica à lentidão, à ineficácia, à improdutividade, à falta de objetividade, aos passes de efeito desnecessários e às firulas para a "arquibancada ver e aplaudir". A velocidade, a ausência de posições e tarefas fixas, a eficiência, a solidariedade, a multiplicidade de funções e a predominância da jogada ensaiada sobre o improviso caracterizam essa nova Bildung esportiva (Gil, 1994: 108).

A produção social do jogador de futebol moderno resulta do poder disciplinar das respetivas instituições das quais são produtos. $\mathrm{Na}$ ausência de figuras representativas desse poder disciplinador foucaultiano (Foucault, 1987) personificado nos treinadores, equipa médica e diretoria os jogos Seca Peli desobedecem os princípios técnicos e táticos, que controlam e disciplinam os corpos. $\mathrm{Na}$ inexistência de horários marcados para as tarefas os corpos não se sujeitam ao tempo e aos critérios de rapidez e eficácia dominante no futebol profissional.

\footnotetext{
${ }^{6}$ Há pelo menos três versões para a origem da expressão "pelada". A primeira diz que viria da palavra pé, por ser jogada, primordialmente, descalça. A segunda, do verbo pelar, pois era comum a antiga bola de borracha, literalmente, pelar os pés, deixando-os vermelhos e ardidos. A mais aceita, no entanto, é a dos campos carecas, pelados ou com ralas gramas, em que o jogo é praticado, em oposto aos tapetes verdes do futebol profissional. No aspecto etimológico, o mais provável é que a palavra seja um derivado de pila, bola em latim, que originou termos como pelota, sinônimo de bola de futebol (fonte: http://www.artefutebol.com.br/qual-a-origem-do-nome-pelada/)
} 
Numa das nossas idas ao terreno um dos moradores nos confidenciou que o espaço em questão é utilizado para a prática de futebol há muito anos. "Quando eu era criança lembro de vir aqui ver as partidas dos jovens da altura e que hoje já são velhotes". Pela fala deste morador que aparenta ter perto de 50 anos, pode-se concluir que este espaço é ocupado para prática de futebol há mais de 30 anos.

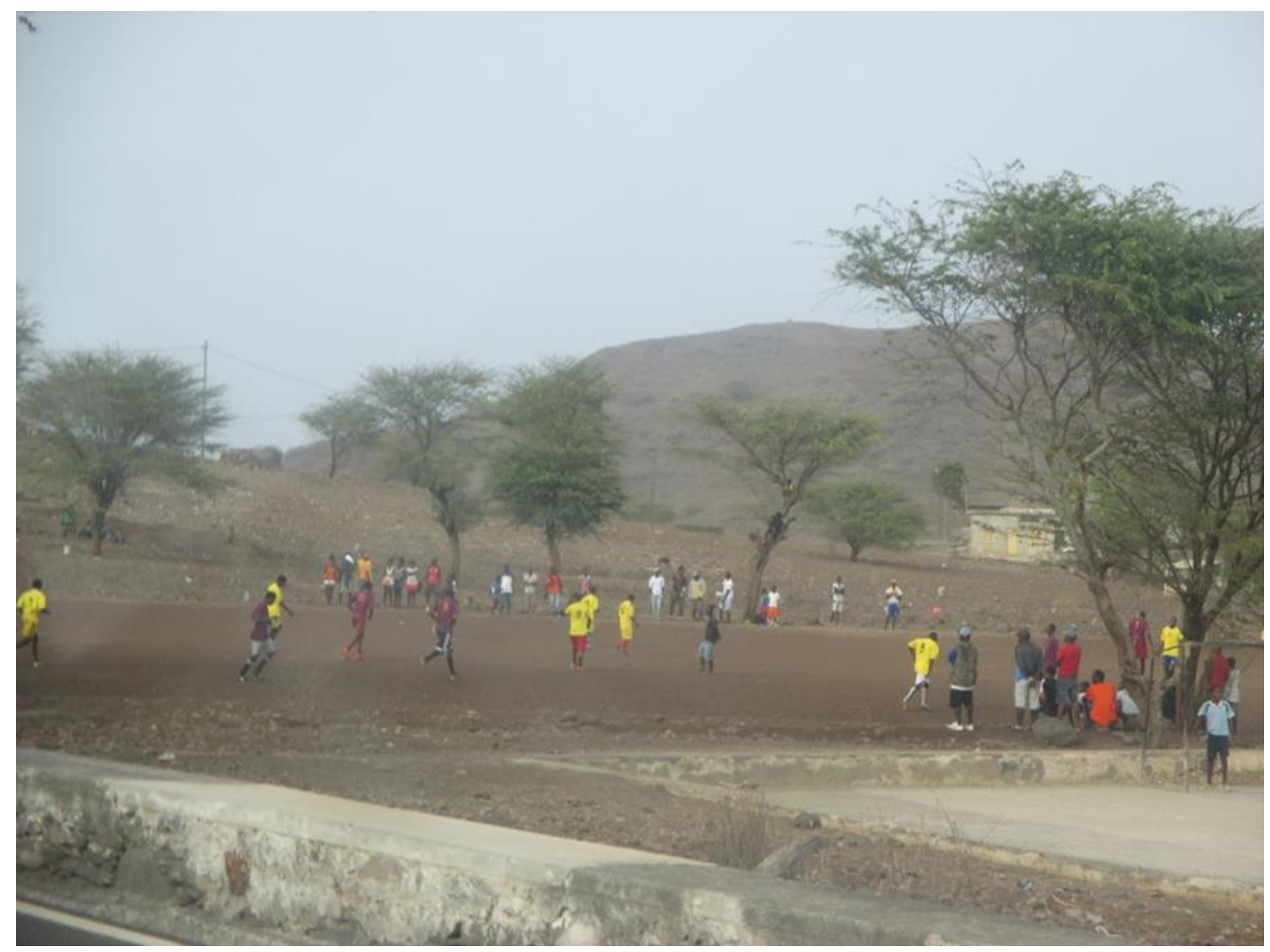

30 de Maio de 2014.

Durante os dias da semana realizam treinos seca peli, sempre no período póslaboral (a partir das 16h00), quando é menor a incidência do sol e nos fins-de-semana organizam torneios e partidas de futebol com a participação de equipas de outras localidades vizinhas e de outros Municípios. As partidas mobilizam uma razoável assistência. Música ao som de potentes caixas altifalantes, cães vadios, crianças deambulando, mulheres no preparo do churrasco, cerveja, convivência, comes e bebes complementam a paisagem. Esta sequência se prolonga até finais de Julho altura em que se retoma os trabalhos agrícolas. Em anos de boa chuva o milheiral é capaz de crescer 
até o limite das traves das balizas tornando quase impercetível para os transeuntes não habituais de que ali convivem ciclicamente futebol e agricultura.

O futebol é um dos maiores eventos da cultura de massa, mobiliza paixões coletivas. Á semelhança de outros países como o Brasil, através do futebol as comunidades se encontram, se organizam, celebram suas festividades, valorizam a cultura local e contribuem para a inclusão social, principalmente de crianças e adolescentes. Através do futebol, tentam muitas vezes recuperar valores comunitários, fatores indispensáveis para uma sociedade com o mínimo de justiça e de dignidade.

Os esportes coletivos em geral e o futebol em particular, por ser considerado o mais popular e democrático dentre todas as modalidades, tem uma importância sociológica que vai além do «jogo em si». Do ponto de vista da História e da Sociologia, o que mais importa no futebol é a sua possibilidade pedagógica, de inclusão e de cidadania. Como é evidente, o futebol nem sempre é aproveitado em suas máximas possibilidades. Contudo, onde se tentou fazer da prática do futebol, um «exercício de cidadania», os resultados foram bem-sucedidos (Murad, 2007: 110).

\section{Simentera, monda e a importância do Sequeiro na cosmologia local}

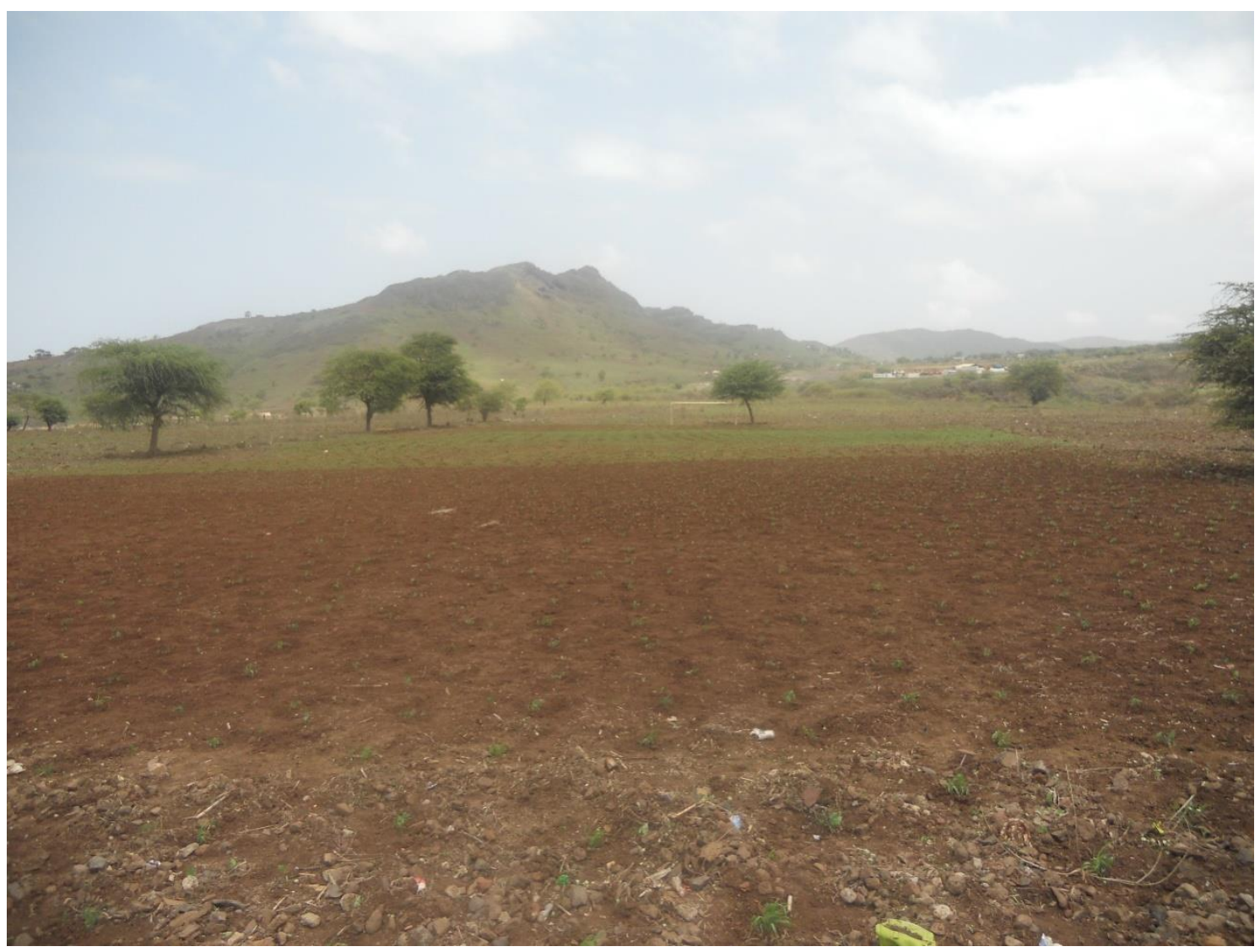

30 de Agosto de 2014 
A partir dos meados de Julho, com o início da época chuvosa, o campo é interditado à prática de futebol e se inicia os preparos do solo com vista ao começo das sementeiras de sequeiro. A agricultura de sequeiro é um sistema de exploração agrícola que se desenvolve sobre ação direta da pluviometria. É caracterizada pela utilização extensiva dos terrenos, mão-de-obra diversificada, e é geralmente praticada nas encostas de declives acentuados. Com efeito tem-se revelado uma atividade de risco e que não assegura, de forma plena, as necessidades locais em termos de cereais e leguminosas. Apesar das suas limitações sobretudo no que toca a produção, é uma atividade importante para a população rural cabo-verdiana, pois é através dela que a população rural garante parte da sua sobrevivência e segurança alimentar.

\footnotetext{
O tipo de cultura à base do milho e sua combinação no campo com culturas leguminosas e fruteiras em "campos promíscuos", revela a necessidade de suprimento de azoto ao campo, ao mesmo tempo que os grãos de milho constituem um cereal com elevado volume de produção por espiga e podem ser guardados vários anos ... (Semedo, 2010: 44).
}

Fruto de um regime fundiário fragmentado, de pequenas propriedades. Da baliza Oeste até o meio do campo é propriedade uma família; da outra metade até a baliza Este a parcela ainda se subdivide entre duas famílias. Não coincidindo nos dias todo o processo de manejo, preparo da terra, sementeira e mondas (capinagem), as plantações geralmente apresentam dinâmicas de crescimento diferenciadas em cada metade do campo.

Se tivermos em conta às condições do solo de Cabo Verde utilizável para agricultura, (43,2\%, está degradado) constatamos que entre os principais problemas, estão o solo pedregoso (27,5\%), seguido da erosão $(7,8 \%)$ e em menor grau, a salinidade $(2,6 \%)$. Estes problemas são mais frequentes na ilha de Santiago, principal responsável pela agricultura de sequeiro, onde o estado de solo pedregoso e a erosão correspondem a 33,7\% e 11,3\%, respetivamente (RGA, 2004). De acordo com Censo Agrícola as terras aptas para a agricultura são estimadas em 44.531ha (RGA, 2004) dos quais $90,8 \%$ são exploradas sob regime de sequeiro, 7,8\% de regadio, e 1,3\% são de regime misto de regadio e sequeiro. Este quadro nos evidencia que existe, por um lado, uma grande carência de solos disponíveis o que consequentemente aumenta a competição pelas melhores parcelas disponíveis e, por outro lado, uma grande dependência da agricultura familiar de pequena escala. 


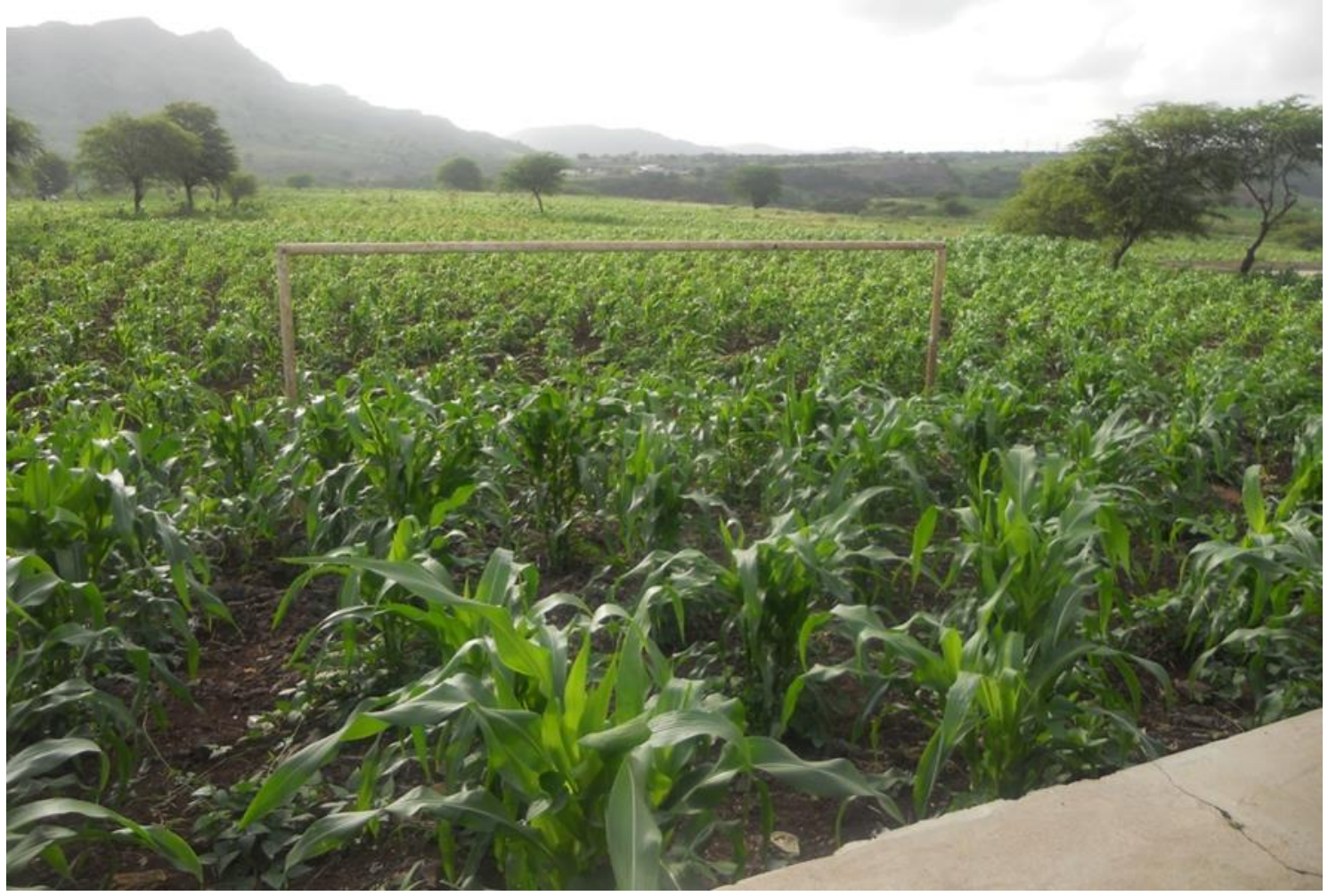

5 de Outubro de 2014.

O campo de Renque Purga, nos retrata um cenário em que predomina uma agricultura familiar de micro-propriedades com uma superfície média muito baixa e que dificulta grandes investimentos. À semelhança do resto do país as parcelas são exploradas na base familiar com a participação dos homens, das mulheres e de todas as gerações. A época agrícola mobiliza também os jovens que preferem sair do campo à procura de outras formas de vida nas cidades. Porém mantêm uma relação com o espaço de origem por via da agricultura sazonal de sequeiro que se pratica em parte na época de verão e das férias laborais (julho/agosto) congregando parentes, redes de amizade e de vizinhança.

Articula-se assim uma dinâmica migratória pendular da cidade para o campo, por períodos limitados, na formatação de uma agricultura a tempo parcial, constituindo-se aquilo que Murteira \& Abreu (1990: 10) caracterizam como sendo "uma população urbanizada que, em períodos de pico de trabalhos agrícolas, se desloca ao campo para efetuar as operações culturais indispensáveis, num espaço de tempo limitado", assegurando de algum modo e na base urbana, a reprodução do sistema de agricultura. 
A agricultura de sequeiro é instrumento e/ou categoria de perceção e compreensão do comportamento e das práticas desses indivíduos.

A colheita do milho verde faz-se geralmente a partir de finais de Outubro e se estende por todo o mês de Janeiro e Fevereiro variando em função da pluviosidade e nível de produção que apresenta alguma irregularidade de ano para ano. Nos primeiros meses faz-se a colheita do milho (cujo ciclo reprodutivo é mais curto) e seguidamente as leguminosas.

\begin{tabular}{|c|c|c|c|c|c|c|c|c|c|c|c|c|}
\hline ATIVIDADES & $\begin{array}{l}\mathbf{M} \\
\mathbf{A} \\
\mathbf{R}\end{array}$ & $\begin{array}{l}\mathbf{A} \\
\mathbf{B} \\
\mathbf{R}\end{array}$ & $\begin{array}{l}\mathbf{M} \\
\mathbf{A} \\
\mathbf{I}\end{array}$ & $\begin{array}{l}\mathbf{J} \\
\mathbf{U} \\
\mathbf{N}\end{array}$ & $\begin{array}{l}\mathbf{J} \\
\mathbf{U} \\
\mathbf{L}\end{array}$ & $\begin{array}{l}\mathbf{A} \\
\mathbf{G} \\
\mathbf{O}\end{array}$ & $\begin{array}{l}\mathbf{S} \\
\mathbf{E} \\
\mathbf{T}\end{array}$ & $\begin{array}{l}\mathbf{O} \\
\mathbf{U} \\
\mathbf{T}\end{array}$ & $\begin{array}{l}\mathbf{N} \\
\mathbf{O} \\
\mathbf{V}\end{array}$ & $\begin{array}{l}\mathbf{D} \\
\mathbf{E} \\
\mathbf{Z}\end{array}$ & $\begin{array}{l}\mathbf{J} \\
\mathbf{A} \\
\mathbf{N}\end{array}$ & $\begin{array}{l}\mathbf{F} \\
\mathbf{E} \\
\mathbf{V}\end{array}$ \\
\hline $\begin{array}{l}\text { Limpeza e alinham } \\
\text { do Campo }\end{array}$ & & & & & & & & & & & & \\
\hline $\begin{array}{l}\text { Inicio dos treinos e } \\
\text { partidas de } \\
\text { confraternização }\end{array}$ & & & & & & & & & & & & \\
\hline $\begin{array}{l}\text { Preparo do solo e } \\
\text { limpeza da área }\end{array}$ & & & & & & & & & & & & \\
\hline Sementeira & & & & & & & & & & & & \\
\hline Capinagem & & & & & & & & & & & & \\
\hline $\begin{array}{l}\text { Colheita de grãos } \\
\text { verdes }\end{array}$ & & & & & & & & & & & & \\
\hline $\begin{array}{l}\text { Colheita de grãos } \\
\text { maduros }\end{array}$ & & & & & & & & & & & & \\
\hline $\begin{array}{l}\text { Recolha de palha e } \\
\text { limpeza da área }\end{array}$ & & & & & & & & & & & & \\
\hline
\end{tabular}

Quadro 1 : Ciclo anual de ocupação do campo de Renque Purga. Fonte: Dados do autor. 


\section{Renque purga no contraciclo do processo de modernização e incentivo ao agronegócio $^{7}$}

Num tempo em que se exorta os agricultores da Ilha de Santiago a criarem empresas de transformação na área da agricultura e pecuária, sustentado na firme convicção de que os processos de modernização (agrícola) vão eliminar a pobreza, a fome, o subdesenvolvimento e as desigualdades sociais de uma forma quase que instantânea, Renque Purga mantem práticas de relação homem/natureza com base em saberes transmitidos de geração em geração e que se suportam em princípio de reciprocidade, cooperação e entreajuda.

O setor agrícola é convidado a se inserir no sistema económico através da sua transformação de um estado considerado ideologicamente "arcaico", tradicional e atrasado, num setor "moderno" e que participa ativamente no crescimento económico do país (Ferreira, 2015). Contudo, esta agricultura categorizada de tradicional deve ser visto como um conjunto de esquemas de perceção, apropriação e ação que é experimentado e posto em prática, tendo em vista as conjunturas de um campo que o estimulam (Setton, 2002).

Para atingir um estágio urbano de modernidade, parâmetro de desenvolvimento por excelência, procura-se assim integrar a agricultura no processo de crescimento económico geral aumentando a produção e sua produtividade, comprando e vendendo à indústria. Esse coloca a agricultura em plano secundário, introduzindo uma série de agentes económicos que crescentemente passam a ter um papel relevante nas relações mercantis e de produção, particularmente na formação de uma indústria química que produz para a agricultura e que dela recebe e cria uma nova noção de alimentos (Almeida, 1999).

\footnotetext{
${ }^{7}$ Convém referir que quando se fala em "agronegócio" em Cabo Verde, os documentos orientadores do setor agrícola (como o PNIA - Programa Nacional de Investimento na Agricultura) apontam como referência os seguintes aspetos: promover o setor agrícola para uma produção orientada para o mercado; utilização de tecnologias modernas para a produção, a transformação e a distribuição, incluindo as tecnologias de informação e da comunicação (TIC); desenvolvimento biotecnológico na pesquisa e sua adaptação, com vista a obter valor acrescentado a todos os níveis da cadeia da produção; desenvolvimento de recursos humanos para melhorar a elaboração e execução de políticas assim como as capacidades de "empresarialização" do setor. Contudo a reduzida dimensão das propriedades, as condições climáticas e infraestuturais não permitem a constituição de grandes propriedades, altamente mecanizadas e conectadas com os mercados internacionais de commodities. Neste caso o termo agronegócio se refere à constituição de pequenas empresas agrícolas, associados à indústrias de transformação para o mercado local e pequenos nichos de produtos tradicionais para exportação, sobretudo para a vasta diáspora constituída por nacionais e seus descendentes, na Europa e nos Estados Unidos.
} 
O homem do campo é assim "promovido" a empresário e homem de negócios. Trata-se de um discurso hegemónico e que não deixa espaço a outras formas alternativas de sobrevivência. E se encaixa dentro de um plano neoliberal de submeter todos setores e todas as atividades produtivas e, em última instância a própria sociedade, às leis do mercado. A noção de desenvolvimento é aqui, no entanto, restritiva, visto que se aplica essencialmente às mudanças e ao progresso das técnicas. Essas noções de desenvolvimento agrícola e rural, portanto, conservam uma significação restrita: primeiro, porque as operações reconhecidas como "de desenvolvimento" referem-se quase que apenas àquelas da produção; segundo, porque os organismos e instituições, oficialmente designados para promover as ações de desenvolvimento, somente agrupam o conjunto de organismos que se dedicam ao desenvolvimento do agronegócio.

\section{Considerações finais}

Num tempo de mudanças e ascensão do capitalismo Renque Purga se afigura como espaço de resistência e de convivência de uma agricultura considerada atrasada e tradicional e dum futebol informal, não profissional e não condizente à reprodução de talentos nos moldes exigidos pelo dito futebol moderno.

Num cenário fundiário de escassez de terras férteis e de pequenas propriedades a comunidade de Renque Purga encontrou um ponto de equilíbrio que tem permitido a coabitação de duas atividades geralmente consideradas incompatíveis.

Produz-se assim um sistema flexível de disposição, não apenas resultado da sedimentação de uma vivência nas instituições sociais tradicionais, mas um sistema em construção, em constante mutação e, portanto, adaptável aos estímulos do mundo moderno. Na trajectoria do Campo de Renque Purga a história se faz na mediação do passado e do presente perante dos desafios de uma identidade social em construção. 


\section{Referências}

ACHUTTI, Luis Eduardo Robinson. Fotos e palavras, do campo aos livros. Studium, n. 12, s/p, 2003. http://www.studium.iar.unicamp.br/12/index_win.html

ALMEIDA, Jalcione. Da ideologia do progresso à ideia de desenvolvimento rural sustentável. In: ALMEIDA, Jalcione e NAVARRO, Zander. Reconstruindo a agricultura: ideias e ideais na perspetiva do desenvolvimento rural sustentável. Porto Alegre, Editora da UFRGS. p. 33-55. 1999. Disponível em: www.ufrgs.br/pgdr

DURAND, Jean-Yves. A Diluição do Consenso: A Água, de "Fonte de Vida" a "Património Colectivo". Etnografia. Revista do centro de Estudos de Antropologia, v. 7, n. 1, p. 15-31, 2003. FERREIRA, Vladmir. Conflitos e Participação no Uso da Água da Barragem de Poilão, Ilha de Santiago, Cabo Verde. Imprensa Nacional de Cabo Verde: Cidade da Praia. 2015,

FOUCAULT, Michel. Vigiar e Punir: nascimento da prisão. $7^{\mathrm{a}}$ ed. Petrópolis: Vozes. 1987.

GIL, Gilson. O drama do futebol-Arte: o oebate sobre a seleção nos anos 70. Revista Brasileira de Ciências Sociais, v. 9, n. 25, p. 100-109, 1994.

MINISTÉRIO DO DESENVOLVIMENTO RURAL. Recenseamento Geral da Agricultura (RGA). Praia: Direção Geral de Planeamento, Orçamento e Gestão - Direção de Estatística e Gestão de Informação. 2004.

MURAD, Mauricio. O futebol no Brasil: reflexões sociológicas. Caravelle, n. 89, p. 109-128, 2007.

MURTEIRA, Mario; ABREU, Armando. A agricultura no desenvolvimento sócio-económico de Cabo Verde. Occasional Paper Series Nr. 1: Comunicação apresentada às "1a Jornadas sobre a Agricultura de Cabo Verde", organizadas pelo Instituto Nacional de Investigação Agrária de Cabo Verde, Instituto de Investigação Científica e Tropical e Instituto Superior de Agronomia, que tiveram lugar em Lisboa em 23/25 de outubro/1990.

RODRIGUES, Francisco Xavier Freire. Modernidade, disciplina e futebol: uma análise sociológica da produção social do jogador de futebol no Brasil. Sociologias, Porto Alegre, v. 6, n. 11, p. 260-299, 2004.

SEMEDO, Joao. Ilha de Santiago (Cabo Verde) - Paisagem natural, uso de recursos naturais e riscos de desertificação. In: Desertificação, Desenvolvimento Sustentável e Agricultura Familiar: Recortes no Brasil, em Portugal e na Africa. João Pessoa - PB Editora Universitária MINISTÉRIO DO MEIO AMBIENTE. p. 29-48, 2010.

SETTON, Maria da Graça Jacintho Setton. A Teoria do Habitus em Pierre Bourdieu: uma leitura contemporânea. Revista Brasileira de Educação, v. 20, maio/jun/Jul/ago, 2002.

VERDUM, Roberto. Temáticas rurais: do local ao regional. In: Roberto Verdum e Luiz Fernando Mazzini Fontoura. Porto Alegre: Editora da UFRGS, 2009. (Disponível em: http://www.ufrgs.br/cursopgdr/downloadsSerie/derad004.pdf).

VERDUM, Roberto. Percepção da Paisagem. Departamento de Geografia Instituto de Geociências Universidade Federal do Rio Grande do Sul, Porto Alegre. 2008 (mimeo).

Recebido em: 28/09/2015.

Aprovado em: 07/03/2016. 